\title{
A Novel Method for Constructing Main-Aftershock Sequences and Its Application in the Global Damage Accumulation Effects Analysis of Gravity Dams
}

\author{
Liaojun Zhang, ${ }^{1}$ Yafei Zhai $\mathbb{D}^{1},{ }^{1}$ Binghui Cui, ${ }^{2}$ Yujie Tang, ${ }^{1}$ and Zhonghui Bi ${ }^{1}$ \\ ${ }^{1}$ College of Water Conservancy and Hydropower Engineering, Hohai University, Nanjing, Jiangsu Province 210098, China \\ ${ }^{2}$ College of Civil and Transportation Engineering, Hohai University, Nanjing, Jiangsu Province 210098, China \\ Correspondence should be addressed to Yafei Zhai; yfzhai@hhu.edu.cn
}

Received 9 January 2020; Accepted 1 February 2021; Published 15 February 2021

Academic Editor: Giuseppe Ruta

Copyright (C) 2021 Liaojun Zhang et al. This is an open access article distributed under the Creative Commons Attribution License, which permits unrestricted use, distribution, and reproduction in any medium, provided the original work is properly cited.

The traditional linear elastic and Drucker-Prager (DP) models cannot truly reflect the strong nonlinear characteristics of the concrete and rock foundation of the dam under earthquake. Therefore, for comprehensive evaluation of the cumulative damage of the gravity dam structure caused by aftershock, the dynamic damage of the dam body concrete is analyzed by many scholars through the plastic damage mechanics method, but there is little research on rock material at the dam foundation with the method utilized; thus, the simulation of the whole dynamic damage evolution is worthy of investigation of the dam body and dam foundation. According to the randomness of ground motion, the transcendental probability (P) is introduced to express the statistical characteristics of aftershock intensity, and a new method for constructing main-aftershock sequences of ground motion is proposed in this paper. And then, the law of the damage evolution and energy characteristics of the concrete gravity dam under the combined action of the main shock and aftershock sequences is studied. The results are shown as follows: the smaller aftershocks do not cause further damage to the dam; as the aftershock intensity increases, the energy characteristics of the dam body and foundation have shown different changing rules; when the ratio of peak aftershock acceleration to peak main shock acceleration ( $\nabla$ PGA) approximately equals 0.68 , the aftershock will cause larger secondary damage to the dam.

\section{Introduction}

The measured data show that strong earthquakes are often followed with lots of aftershocks. After the severe damage of the structure caused by the strong main shock, the damage of the structure will be aggravated by the strong aftershock. This repeated damage will be undoubtedly worse than the damage caused by the single main shock, which calls for higher requirements on the seismic performance of the structure [1]. Many post earthquake investigations also reveal that the damage to structures caused by aftershocks can not be ignored [2-5]. However, the current seismic design code [6] only considers the action of the main shock, while the secondary damage of the dam structure caused by the strong aftershocks is ignored. This may lead to insufficient earthquake resistance of the dam structure under the main- aftershock sequence. Once the dam is damaged in the earthquake, it will not only endanger the safety of the project itself but also bring immeasurable loss to people's life and property safety in the downstream. Studying the effects of aftershocks on the dynamic characteristic of the concrete gravity dam is helpful to comprehensively and accurately assess the seismic resistance of large dam projects.

Due to the lack of the record of the main-aftershocks in practice, many scholars mostly use the main-aftershocks of tectonics in their research. Therefore, it is vital to developing a reasonable method of seismic ground motion construction based on main-aftershocks sequences. For major projects, according to the probability analysis of seismic hazards, the main seismic parameters of the foundation rocks of the engineering site under different transcendence probabilities can be obtained. So, the core of constructing the main- 
aftershock sequence is to determine the seismic parameters of the aftershock sequence. It should be noted that the magnitude and location of aftershocks depend on the main shock [7]; in this way, more consistency can be maintained in the probability seismic risk analysis of the main-aftershock. Different scholars have proposed different methods of seismic ground motion construction. Das et al. [8] studied the aftershock and main shock ground motion parameters and gave the relationship between the two parameters; however, they only chose Chi-Chi earthquake records and did not consider the saturation effect in the near-field region. Boore et al. [9] did not consider the relationship between the main shock and aftershock ground motion parameters. Graizer and Kalkan [10] did not tell the difference between the main shock and aftershock when establishing the attenuation relationship of ground motion. Vahedian et al. [11] used the artificial neural network method to generate aftershock ground motion. Actually, due to the randomness of earthquakes and the complexity of their seismogenic mechanism, probabilistic analysis can better describe the actual situation. Combined with the seismic risk analysis method, it should be more practical to analyze the effect of aftershocks with different transcendental probabilities on the cumulative damage of structures. However, in the existing methods of main-aftershock sequences ground motion construction, no scholars have quantitatively described the transcendental probability of aftershocks with different intensities. In addition, the influence of duration and intensity envelope is also rarely considered. This paper considers the above factors comprehensively and proposes a new construction method of the main-aftershock sequences ground motions.

At present, scholars have analyzed and studied the seismic performance of the structure under the action of the main-aftershock. Alliard and Leger [12] studied the effect on the drainage efficiency of gravity dams considering the aftershocks. Wang and Zhang [13] analyzed the effects of the main-aftershock seismic sequences on the dynamic characteristic of gravity dams. Wang et al. [14], respectively, analyzed the damage evolution of the gravity dam under the action of the main shock, aftershock, and main-aftershock. Abdollahzadeh et al. [15] evaluated the seismic performance of reinforced concrete structures under the action of main and residual earthquakes. In the current study, the linear elastic and Drucker-Prager (DP) model is mainly used to simulate the dam foundation. Actually, microfissures are randomly distributed in the dam foundation rock mass, whose tensile strength is lower than that of the dam concrete. Therefore, the damage analysis to dam foundation rock is an important part for the nonlinear dynamic analysis of the high-dam multicoupling system [16]. At present, there is no literature about the influence of aftershock on the whole dam foundation damage under different transcendental probabilities by using the damage mechanics model. In this paper, the whole damage model of the gravity dam is established based on an actual project. Using the construction method proposed in this paper, main-aftershock earthquake waves are constructed and synthesized. The cumulative damage of gravity dams subjected to strong aftershocks with different transcendental probability after the main earthquake is analyzed. This study quantifies the effect of aftershocks on the whole dynamic damage to the dam body and foundation under different transcendental probabilities and reveals the evolution law of the whole damage of dam body and dam foundation under different aftershocks.

\section{Study on Construction Method of the Main- Aftershock Sequence}

In this paper, the main-aftershock (mainshock-aftershock) sequence is defined as the combination of the largest aftershock after the main shock and the main shock; that is, the sequence of two shocks is superimposed. There will be dozens or even hundred of aftershocks after the strong main shocks; some scholars have found that smaller aftershocks have less impact on the further damage of the dam. Therefore, the main-aftershock sequence relationship in this paper mainly considers the influence of the largest aftershock after the main shock. This paper combines the statistical results of the main shock and aftershock and attenuation relation of aftershock ground motion, introducing transcendental probability function to express statistical characteristics of aftershock intensity. At the same time, the attenuation law of the envelope function and the effect of the duration of the ground motion are considered. The process of the proposed seismic method for the mainaftershock sequence is as follows.

(1) Determine the (max) aftershock magnitude according to the statistical relationship between the main earthquake magnitude and the aftershock magnitude.

(2) Choose the appropriate attenuation relationship of aftershock ground motion according to the magnitude, the epicenter distance, and site characteristics of the main shock. The transcendental probability (P) is introduced to express the aftershock intensity. The parameters of aftershock such as PGA and PSA under different transcendental probability are predicted.

(3) According to the magnitude and the epicenter distance of the main shock and aftershock obtained, determine the duration and intensity envelope functions. The main-aftershock sequence can be obtained by combining the time history of the main and aftershock seismic sequences.

2.1. Magnitude Statistical Relationship between Main Shock and Aftershock. Magnitude is one of the most commonly used parameters to describe the magnitude of earthquakes and the characteristics of earthquakes. In [17], based on the definition of strong aftershock, data of 123 earthquakes with magnitude 6 or above satisfying the principle of defining strong aftershock in the world are collected, after the regression analysis by the least square method. The regression relationship between the main shock magnitude $\left(M_{m}\right)$ and the strong aftershock magnitude $\left(M_{a}\right)$ is obtained as follows: 


$$
M_{a}=0.643 M_{m}+1.40 .
$$

Using the statistical formula of variance, the unbiased estimation of variance for linear regression equation (1) is obtained $\sigma^{2}=0.18$. The difference between the maximum aftershock magnitude and the main shock magnitude is mostly in accordance with the bath's law of about 1.2.

\subsection{Attenuation Relation of Aftershock Seismic Ground Mo-} tion Parameters. Zhai and Xie [18] selected 1353 main shock and aftershock ground motions from 19 main-aftershocks sequences to analyze the characteristics that the ratio of aftershock ground motion parameters to main shock ground motion parameters changing with magnitude, the fault distance, and site. Based on the existing attenuation relations, the following attenuation relation of the aftershock ground motion parameters is proposed:

$$
\begin{aligned}
\ln (\nabla Y)= & b_{1} M_{m s}+b_{2} \nabla M+b_{3} \ln \left[\nabla D+\left(\nabla M / D_{m s}\right)^{b_{4}}\right] \\
& +b_{5} \ln \left(760 / V_{30}\right)+\varepsilon .
\end{aligned}
$$

In this formula, $\nabla Y$ represents the ratio of the aftershock parameter $\left(Y_{a s}\right)$ to the main shock parameter $\left(Y_{m s}\right) ; \nabla M$ is the ratio of aftershock magnitude $\left(M_{a s}\right)$ to main shock magnitude $\left(M_{m s}\right) ; \nabla D$ is the ratio of aftershock fault distance $\left(D_{a s}\right)$ to the main shock fault distance $\left(D_{m s}\right) ; V_{30}$ is the average shear-wave velocity of $30 \mathrm{~m}$ underground; and $\varepsilon$ is described as the residual between the predicted and observed values. Assuming that it obeys the normal distribution of mean value 0 and standard deviation $\sigma, b_{1} \sim b_{5}$ are the fitting coefficients of the formula.

The first and second terms on the right side of the equation are used to describe the variation of $\nabla Y$ with the magnitude of the main shock and aftershock. In the third term, $\ln \nabla D$ denotes the geometric decay of $\nabla Y$ with the ratio of fault spacing. $\nabla M / D_{m s}$ is used to simulate the near-field saturation effect. And, the fourth item is used to simulate the effect of site type on $\nabla Y$. Equation (2) is relevant to the main shock parameters; thus, the model can conveniently predict the parameters of aftershock ground motion, as well as reveal the relationship among the parameters of the main shock and aftershock.

In fact, because of the randomness of earthquakes and the complexity of their seismogenic mechanism, when using statistical laws to predict the parameters of aftershock ground motions, the probability analysis method can better describe the actual situation. Thus, the statistical law of aftershock intensity expressed by the peak acceleration transcendence probability $P$ of aftershock is proposed in this paper when constructing the parameters of aftershock ground motion. In the calculation, it is assumed that the epicenter location of the main shock is close to that of the aftershock.

$$
\text { Let } \begin{aligned}
z= & b_{1} M_{m s}+b_{2} \nabla M+b_{3} \ln \left[\nabla D+\left(\nabla M / D_{m s}\right)^{b_{4}}\right] \\
& +b_{5} \ln \left(760 / V_{30}\right) .
\end{aligned}
$$

Relative parameter $\nabla Y$ of aftershock ground motion in equation (2) is expressed as relative peak acceleration of the main-aftershock ground motion $\nabla$ PGA (the ratio of aftershock peak acceleration to main shock peak acceleration). Given that $\varepsilon \sim \mathrm{N}\left(0, \sigma^{2}\right), z+\varepsilon \sim \mathrm{N}\left(z, \sigma^{2}\right)$, joint equations (2) and (3) can be obtained $\nabla \mathrm{PGA}=\mathrm{e}^{z+\varepsilon}$, where $\nabla$ PGA obeys $\log -$ normal distribution. The probability density function equation (4) and cumulative distribution function equation (5) of relative peak acceleration $\nabla$ PGA of the main shock and aftershock ground motions can be obtained by calculation.

$$
f(x)= \begin{cases}\frac{1}{\sqrt{2 \pi} x \sigma} \exp \left[-\frac{1}{2 \sigma^{2}}(\ln x-z)^{2}\right], & x>0, \\ 0, & x \leq 0 .\end{cases}
$$

Cumulative distribution function

$$
P(x)=\frac{1}{2}+\frac{1}{2} \operatorname{erf}\left[\frac{\ln (x)-z}{\sigma \sqrt{2}}\right] .
$$

Then, $\nabla$ PGA's transcendence probability $\mathrm{P}$ is derived out, as the following equation:

$$
P=1-P(x)=\frac{1}{2}-\frac{1}{2} \operatorname{erf}\left[\frac{\ln (x)-z}{\sigma \sqrt{2}}\right] .
$$

When calculating, different transcendental probabilities $\mathrm{P}$ can be selected to determine the corresponding ground motion strength parameter $\nabla$ PGA for analysis.

2.3. Law of Attenuation of Earthquake Intensity. Earthquake duration can be divided into three phases, the initial ground motion increases rapidly from small to large, followed by the continuous stage of strong earthquake and then the slow attenuation stage. Intensity nonstationary is the characteristic of seismic wave changing with time. If the peak points of acceleration time history are connected, the envelope function $f(t)$ can be obtained. The time course of earthquake motion $a(t)$ can be expressed as follows:

$$
a(t)=x(t) \cdot f(t)
$$

where $x$ is expressed as a stationary random process.

Envelope function $f(t)$ adopts the segmented model proposed by Amin and Ang [19]:

$$
f(t)= \begin{cases}\left(\frac{t}{t_{1}}\right)^{2}, & 0 \leq t<t_{1}, \\ 1, & t_{1} \leq t<t_{2}, \\ e^{-c\left(t-t_{2}\right)}, & t_{2} \leq t<t_{d},\end{cases}
$$

where $t_{1}$ and $t_{2}$ represent the start and end time of strong earthquake duration, respectively; $c$ represents the attenuation coefficient; the peak stationary time $t_{s}=t_{2}-t_{1} ; t_{d}$ is the total holding time; and attenuation time of seismic amplitude $t_{c}=t_{d}-t_{2}\left(k=0.2\right.$, where $\left.t_{c}=-\operatorname{lnk} / c\right)$. 
The envelope parameters $t_{1}, t_{2}$, and $c$ are related to the earthquake mechanism, the propagation path of ground motion, and the site parameters. Huo [20] selected 457 strong earthquake records for statistical analysis and obtained the regression reationship among envelope parameters on bedrock site, magnitude, and epicenter distance.

$$
\left\{\begin{array}{l}
\lg t_{1}=-1.074+1.005 \lg (R+10), \\
\lg t_{s}=-2.268+0.3262 M+0.5815 \lg (R+10), \\
\lg c=1.941-0.2871 M-0.567 \lg (R+10),
\end{array}\right.
$$

where $M$ and $R$ are, respectively, represented as magnitude and epicenter distance.

2.4. An Example of the Main-Aftershock Sequence Construction. Taking a concrete gravity dam project as an example, the main-aftershock sequence ground motion is constructed. In the project, the design earthquake is based on the ground motion parameters with a probability of $2 \%$ over the base period of 100 years, and the peak acceleration of the site design bedrock is $0.316 \mathrm{~g}$. The corresponding earthquake magnitude $M_{m}$ is 7.3. The epicenter distance $D_{m s}$ is $25 \mathrm{~km}$, and the average underground shear-wave velocity $V_{30}$ of $30 \mathrm{~m}$ in bedrock is $1300 \mathrm{~m} / \mathrm{s}$. The aftershock magnitude can be obtained from equation (1), and the maximum aftershock magnitude is $6.09(\nabla M=0.843)$. In reference [21], homologous earthquakes are selected for main shock and aftershock, corresponding $\nabla D=1$. According to equation (3), $Z=-0.735$. The standard deviation $\sigma=0.569$ is known from reference [18]. Substitute the data into equations (4) and (6). The probability density function and cumulative distribution function are derived out, as shown in the following equations:

$$
\begin{aligned}
f(x) & = \begin{cases}\frac{1}{1.426 x} \exp \left[-1.543(\ln x+0.735)^{2}\right], & x>0 \\
0, & x \leq 0\end{cases} \\
P & =\frac{1}{2}-\frac{1}{2} \operatorname{erf}\left[\frac{\ln (x)+0.735}{0.805}\right] .
\end{aligned}
$$

Figures 1 and 2 are probability density function curves and transcendental probability function curves, respectively.

This paper takes the aftershock PGA transcendence probability $P=50 \%$ as an example, corresponding relative acceleration of the main shock and aftershock is $\nabla \mathrm{PGA}=0.479$. Let $\nabla Y=\nabla S a$, and take the site bedrock acceleration response spectrum (PSA) as the main shock acceleration response spectrum, substituting it into equation (2) to obtain the acceleration response spectrum of aftershock site, as shown in Figure 3. According to the attenuation relation of strength envelope equation (5), the duration of the main shock and aftershock ground motions is calculated to be $33 \mathrm{~s}$ and $22 \mathrm{~s}$, respectively. The main-aftershock earthquake waves with nonstationary characteristics are synthesized (with a damping ratio of 5\%). The interval between the main shock and

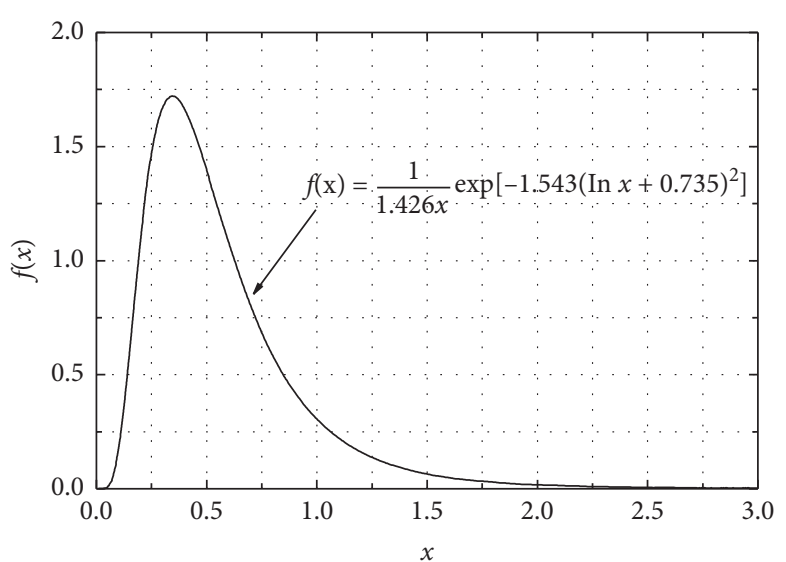

FIgure 1: Probability density function curve.

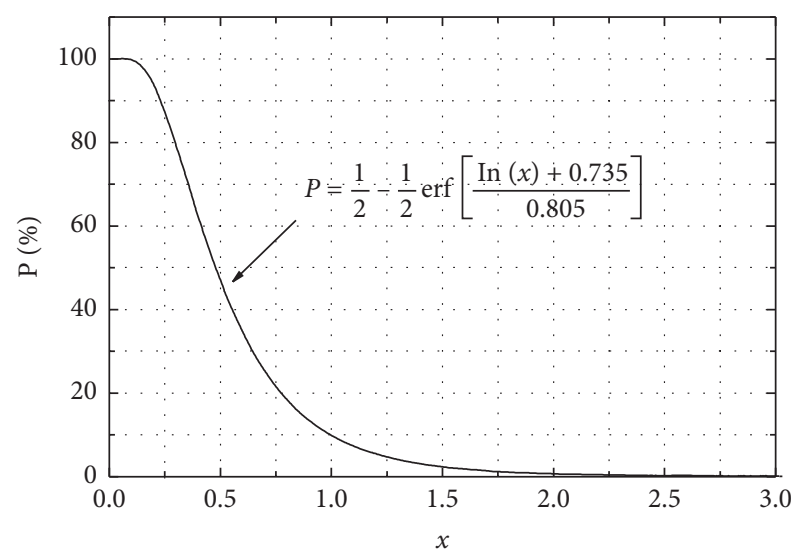

FIgURE 2: Transcendental probability function curves.

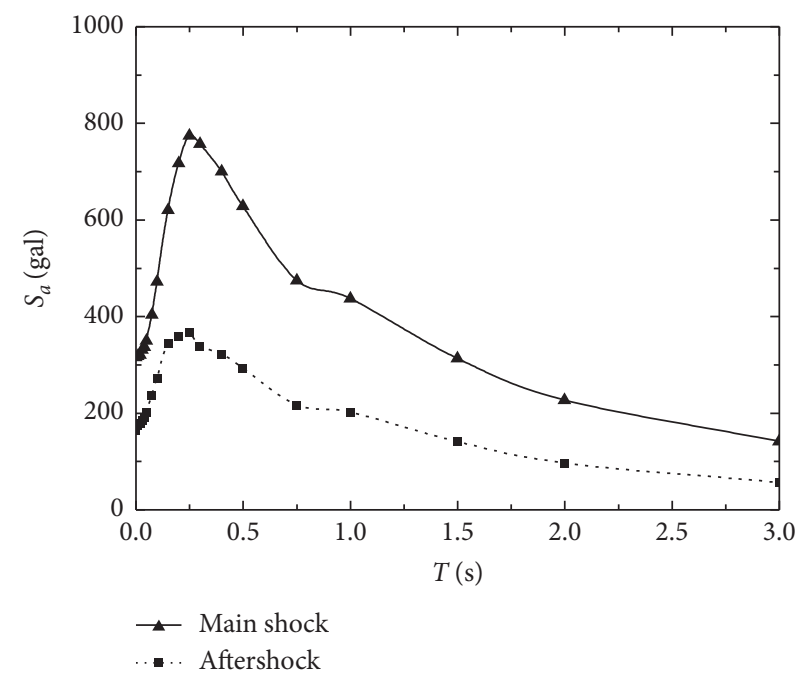

FIgURE 3: Acceleration response spectrum.

aftershock ground motions is $10 \mathrm{~s}$, and then the seismic waves are combined. Taking $\nabla P G A=0.479$ as an example, the acceleration time history curve of horizontal principal residual 
sequence seismic wave is shown in Figure 4. T1, T2, and $T 3$ in the figure represent the duration of the main shock, the time interval between the main-aftershock, and the duration of the aftershock, respectively. Peak acceleration of vertical seismic wave takes $2 / 3$ of horizontal.

\section{Damage Evolution Law of Dam under Main- Aftershock}

3.1. Plastic Damage Model of Concrete. Model constitutive relationship is as follows [22]:

$$
\sigma=(1-d) D_{0}^{\mathrm{el}}:\left(\varepsilon-\widetilde{\varepsilon}^{p l}\right),
$$

where $\sigma$ and $d$ are expressed as stress and damage variables, respectively; $\varepsilon$ and $\widetilde{\mathcal{E}}^{\mathrm{pl}}$ are the elastic and plastic strains; and $D_{0}^{\mathrm{el}}$ is the initial elastic stiffness.

The elastic modulus after damage is calculated by the following formula:

$$
E=(1-d) D_{0}^{\mathrm{el}}
$$

The yield equation is expressed as follows:

$F=\frac{1}{1-\alpha}\left(\bar{q}-3 \alpha \bar{p}+\beta\left(\widetilde{\varepsilon}^{p l}\right)\left\langle\widehat{\sigma}_{\max }\right\rangle-\gamma\left\langle-\widehat{\sigma}_{\max }\right\rangle\right)-\bar{\sigma}_{c}\left(\widetilde{\varepsilon}^{p l}\right)=0$,

$\beta=\frac{\bar{\sigma}_{c}\left(\widetilde{\varepsilon}_{c}^{p l}\right)}{\bar{\sigma}_{t}\left(\widetilde{\varepsilon}_{t}^{p l}\right)}(1-\alpha)-(1+\alpha)$,

where $\alpha$ and $\gamma$ are material constants; $\bar{p}=-(1 / 3) \operatorname{tr} \bar{\sigma} ; \bar{\sigma}$ is the effective stress tensor parameters; $\bar{\sigma}_{c}$ and $\bar{\sigma}_{t}$ are effective compressive stress tensor and tensile stress tensor, respectively; $\overline{\bar{\sigma}}_{\max }$ is the maximum eigenvalue of $\bar{\sigma}$; and $\bar{q}$ is the effective Mises equivalent stress.

3.2. Model Validation. A simple uniaxial tension compression and tension compression cycle problem is numerically verified and compared with the existing experiments $[22,23]$. The model adopts the following material parameters: modulus of elasticity $E_{0}=3.1 \times 104 \mathrm{MPa}$, tensile strength $F_{t}=3.48 \mathrm{MPa}$, and fracture energy $G_{f}=40 \mathrm{~N} / \mathrm{m}$. The unit feature length $L_{t}=82.6 \mathrm{~mm}$.

Figure 5 shows the comparison between the uniaxial cyclic load test data and the numerical simulation results. The test data are the local area data measured by the wide strain gauge; if the average stress-strain relationship in the small local area is considered, the absolute value of the post peak curve slope of the final test data will be reduced. Since the stress curve is assumed to be the difference of two exponential functions, the slope of the numerical simulation curve after the peak in the tensile stress-strain curve is more gentle than the test data. It can be seen that the numerical results can well simulate the stress-strain curve of concrete under uniaxial tension cyclic load. The stiffness degradation of the model material is simulated in each unloading and loading cycle. It can be seen from Figure 6 that the stiffness decreases after tensile damage under cyclic load; the

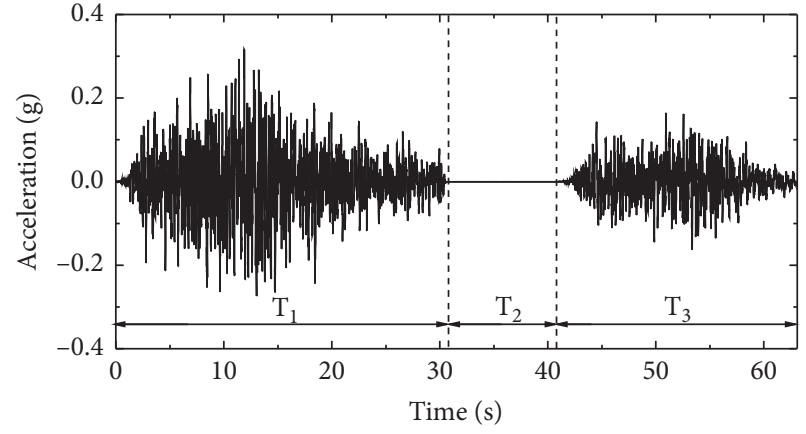

FIGURE 4: Horizontal seismic wave acceleration time history curve.

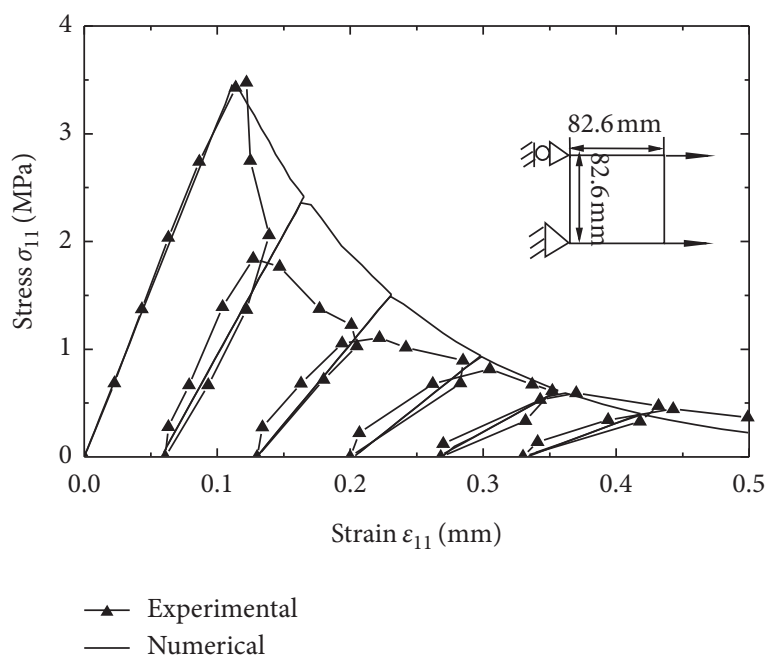

FIGURE 5: Cyclic tensile stress-strain curve of concrete.

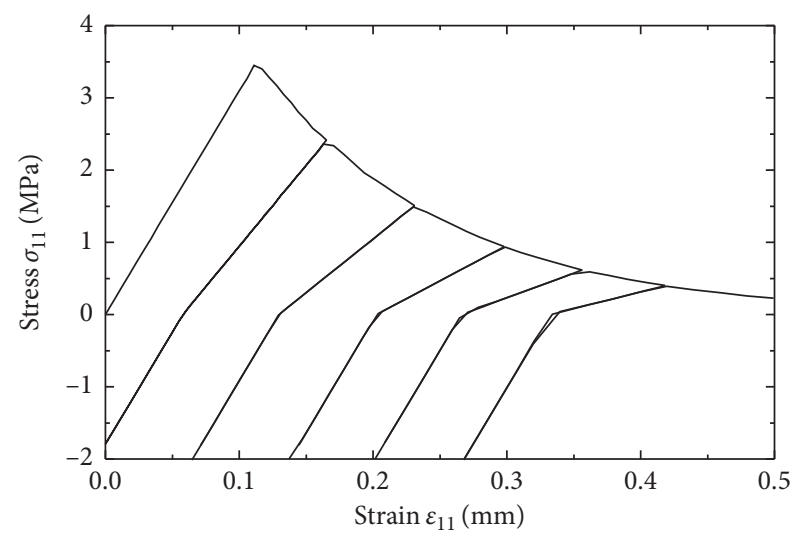

FIgURE 6: Stress-strain curve of tension compression cycle.

"unilateral effect" of concrete can be well reflected by the continuous reverse pressure and the recovery of elastic modulus in the compression zone.

3.3. Damage Mechanics Model and Damage Evolution Law of Dam. In this paper, a mechanical model for the whole dynamic damage of gravity dams is established. Using the 
method of seismic ground motion construction for the main-aftershock sequence proposed in Section 1, the simulated earthquake wave of the main-aftershock sequence is constructed and synthesized. The nonlinear dynamic response of concrete gravity dams with different aftershock transcendental probabilities is studied.

3.3.1. Computational Model and Method. Select a dam section of the above concrete gravity dam as the analysis object. The height of the dam is $97 \mathrm{~m}$, and the water depth of the normal pool level is $83 \mathrm{~m}$. C20 concrete is used below $50 \mathrm{~m}$ of the dam body, and C15 concrete is used above $50 \mathrm{~m}$ of the dam body. Geological survey shows that $0-10$ below the dam site is class III rock, and the others belong to class II rock. The finite element model of the gravity dam was established based on the ABAQUS finite element software (Figure 7). Both the dam body and the dam foundation use CPE4R elements. The model is divided into 8913 nodes and 8658 elements. Material parameters of class II rocks are $f=1.25$ and $c=1.6 \mathrm{MPa}(f=\tan \varphi$, same as below). Material parameters of class III rocks are $f=1.10$ and $c=1.15 \mathrm{MPa}$. Tensile strength of dam foundation rock mass is deduced by using $f_{t}=2 c \cdot \cos \varphi /(1+\sin \varphi)$ in $\mathrm{M}-\mathrm{C}$ criterion.

Considering both vertical and horizontal seismic waves, the mass damping coefficient and stiffness damping coefficient are calculated with the damping ratio of $5 \%$. Viscoelastic artificial boundaries are set on both sides and bottom of the model foundation to simulate the influence of wave energy dissipation to infinite ground under the action of earthquakes. Assuming the incompressibility of the reservoir water, the Westergaard additional mass method is used to simulate the hydrodynamic pressure. Reference [24] obtains the damage parameters of the dam concrete material and obtains the damage parameters of the bedrock material by corresponding reduction of the concrete damage curve relative to the tension strength of rock [16]. After considering the effect of seismic energy escaping to far-field, damage response of dam body-foundation integral structure under earthquake action of the main and aftershock is analyzed. The concrete and bedrock material parameters used in the calculation are shown in Table 1.

3.3.2. Effects of the Main-Aftershock on Damage Evolution of Gravity Dams. In order to study the damage evolution law of gravity dams under different main-aftershock sequences, based on the sequence of the main-aftershock constructed in Section 2.4, this paper increases the value of transcendence probability $\mathrm{P}$ for the aftershock intensity. Given that aftershock ground motion intensity is generally smaller than main shock ground motion; the values of $\mathrm{P}$ in this paper are $60 \%, 40 \%, 30 \%, 25 \%, 20 \%, 15 \%$, and $10 \%$, respectively. By equation (2), the corresponding $\nabla \mathrm{PGA}$ is $0.415,0.555,0.645$, $0.705,0.775,0.865$, and 0.990 , respectively. Eight kinds of conditions including single action of main shock and combined action of main and aftershocks are selected for calculation and research.

The calculation results are shown in Figure 8. The blue area indicates that no damage has occurred, and the red area

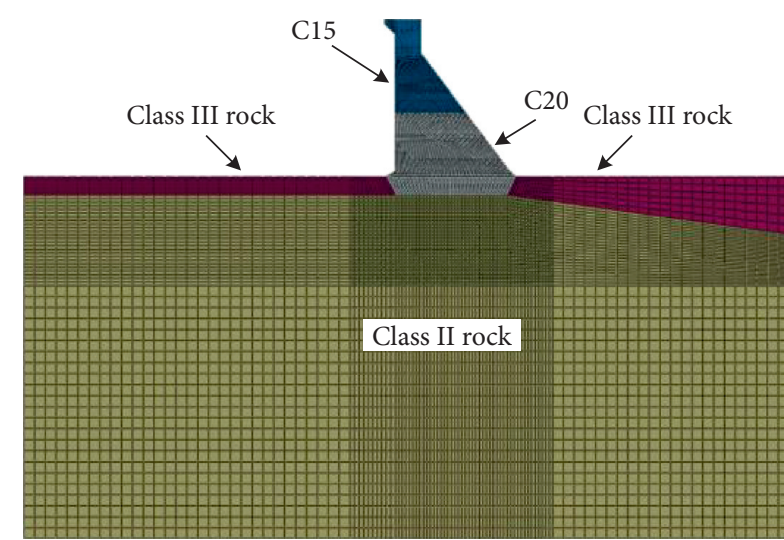

FIGURE 7: Finite element analysis model of gravity dam.

TABle 1: Material parameters.

\begin{tabular}{lcccc}
\hline Material & C15 & C20 & Class II & Class III \\
\hline$\rho\left(\mathrm{kg} / \mathrm{m}^{3}\right)$ & 2400 & 2400 & 2675 & 2625 \\
$E_{d}(\mathrm{GPa})$ & 34.50 & 37.5 & 14 & 7 \\
$\mathrm{~N}$ & 0.17 & 0.18 & 0.22 & 0.24 \\
$f_{t}(\mathrm{MPa})$ & 1.20 & 1.61 & 1.12 & 0.88 \\
$G_{f}(\mathrm{~N} / \mathrm{m})$ & 90 & 120 & & \\
\hline
\end{tabular}

indicates that damage cracks have occurred at this location. Under different conditions, the damage locations of concrete gravity dams are roughly the same. The damage cracks of the concrete material of the dam body mainly appear in the downstream slope change, and the bedrock cracks at the dam heel extend downward along the depth direction. Under the action of single main shock, the damage crack at the downstream slope change extends to upstream and downward. Finally, the concrete crack at the downstream slope change extends about $5.2 \mathrm{~m}$ upstream and about $7.5 \mathrm{~m}$ downward, and the bedrock cracks at the dam heel extend downward $37.2 \mathrm{~m}$. When the transcendence probability of aftershock PGA is high (the aftershock intensity is small), under the main-aftershock (condition $\mathrm{a} \sim \mathrm{c}$ ), the damage areas of the dam body and dam foundation have no obvious change compared with those under a single main shock. With the decrease in aftershock PGA transcendence probability (condition $\mathrm{d} \sim \mathrm{g}$ ), that is, the aftershock intensity increases, the damage areas of the dam body and foundation have increased. Take condition $g$ as an example, when the ground motion ends, the concrete crack at the downstream slope change extends about $10.2 \mathrm{~m}$ upstream and about $8.5 \mathrm{~m}$ downward and the bedrock cracks at the dam heel extend downward $46.5 \mathrm{~m}$.

\section{Dissipated Energy Characteristics of Gravity Dam under Main-Aftershock}

Under the action of earthquakes, damage to concrete materials of dams and rock materials of dam foundations will accumulate in the form of dissipated energy. Damage evolution process of dam structure is closely related to the 


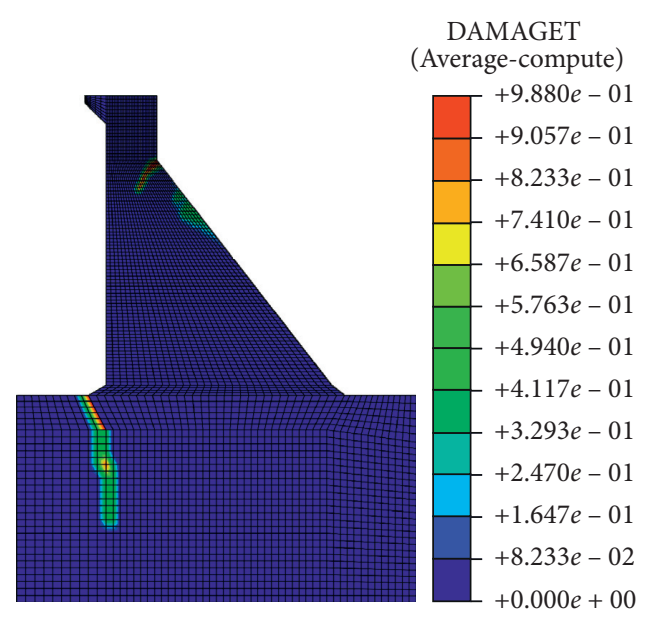

(a)

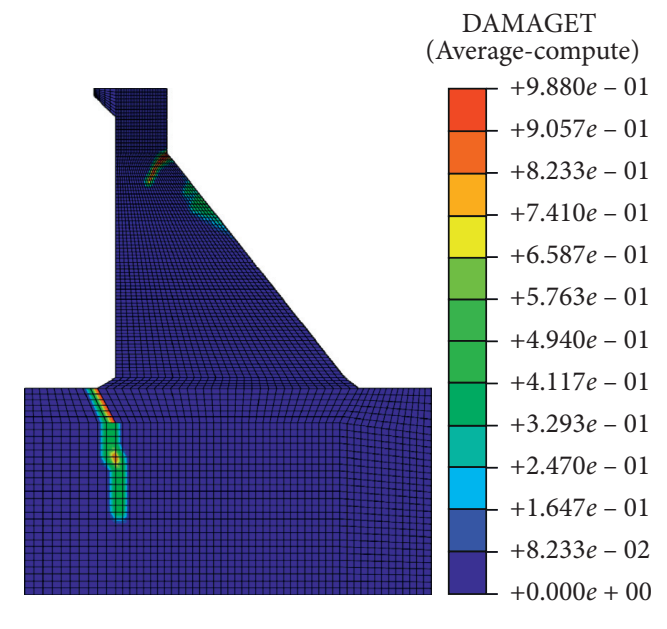

(c)

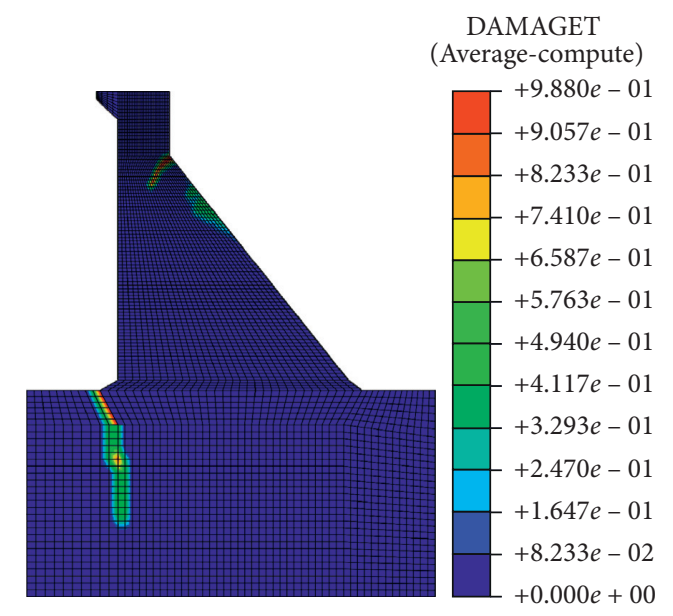

(e)

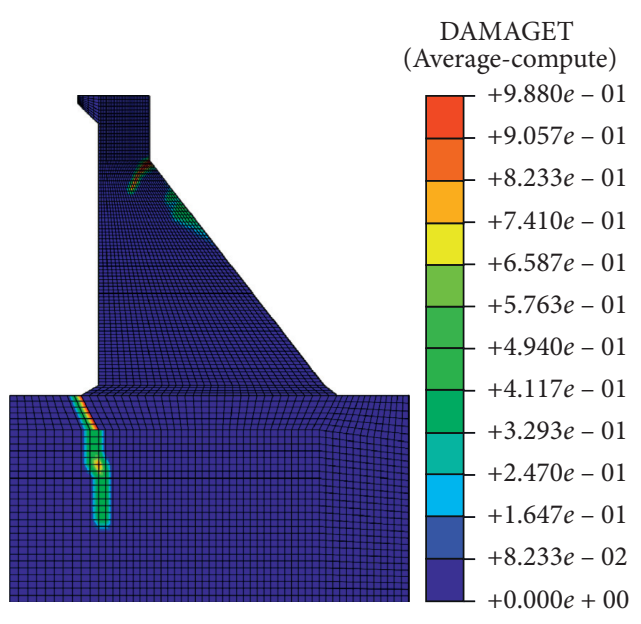

(b)

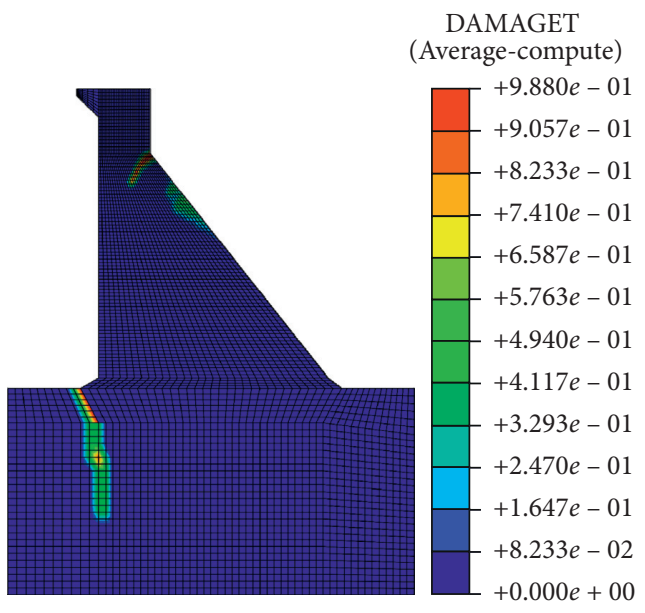

(d)

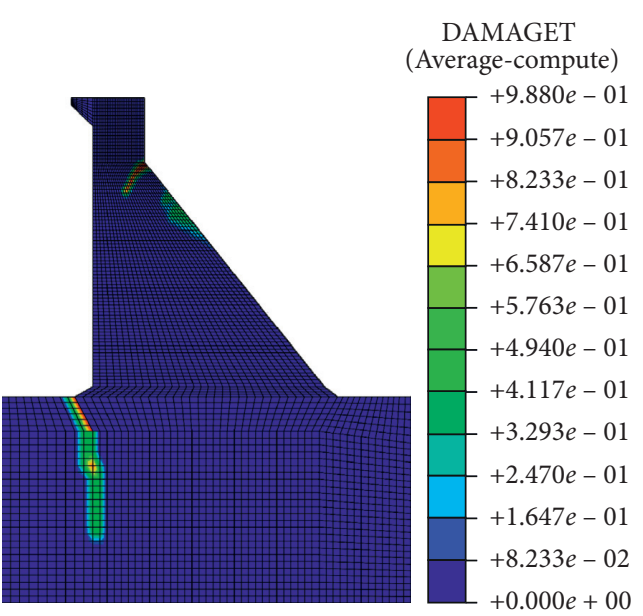

(f)

Figure 8: Continued. 


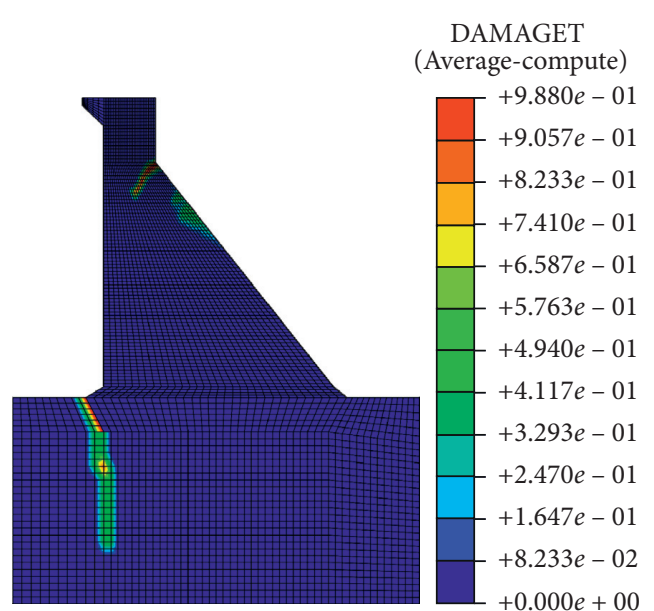

(g)

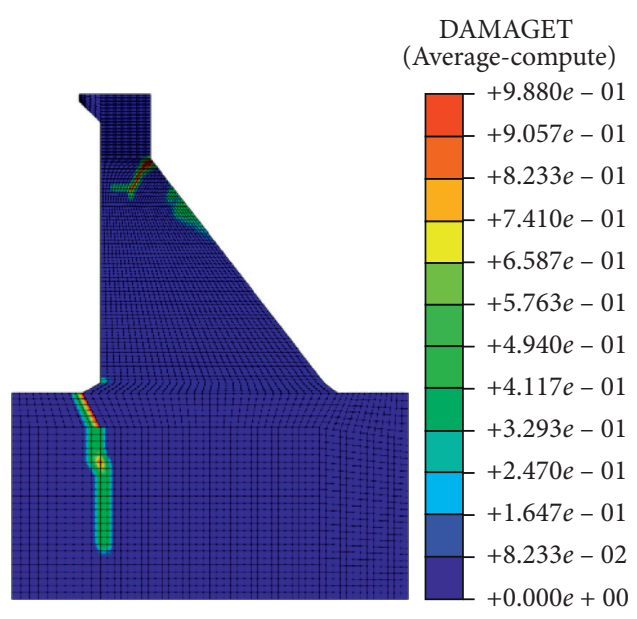

(h)

Figure 8: Dam damage zone under single main shock and main-aftershock. P represents the transcendence probability of aftershock PGA.. (a) Single main shock action. (b). $P=60 \%$. (c) $P=40 \%$. (d) $P=30 \%$. (e) $P=25 \%$. (f) $P=20 \%$. (g) $P=15 \%$. (h) $P=10 \%$.

process of dissipated energy [25, 26]. Therefore, understanding the energy changes of the structure in the whole time history of main-aftershock sequence is of great significance to the damage of the cognitive structure under the action of main-aftershock sequence. Based on the plastic damage model, this paper analyzes and compares the dissipated energy characteristics of concrete gravity dams with different aftershock transcendence probability levels.

4.1. Dissipated Energy Equation. The dynamic equilibrium equation under earthquake action is shown in the following equation [26]:

$$
\mathbf{M} \ddot{\mathbf{u}}_{\mathrm{t}}+\mathbf{C} \dot{u}+\mathbf{r}=\mathbf{p}
$$

where $\mathbf{M}$ is the mass matrix, $\mathbf{C}$ denotes the damping matrix, $\mathbf{r}$ denotes the vector of restoring forces, $\mathbf{p}$ denotes the vector of preseismic applied loads, and the vector $\ddot{\mathbf{u}}_{\mathrm{t}}$ represents the absolute acceleration, which is the sum of the relative acceleration, $\ddot{\mathbf{u}}$, and the ground acceleration, $\ddot{\mathbf{u}}_{\mathrm{g}}$. Integrating the relative displacement $u$ on both sides of equation (16), the dynamic equilibrium between energy components can be expressed as

$$
\frac{1}{2} \dot{\mathbf{u}}_{t}^{\mathrm{T}} \mathbf{M} \ddot{\mathbf{u}}_{\mathrm{t}}+\int \dot{\mathbf{u}}^{\mathrm{T}} \mathbf{C d} u+\int \mathbf{r}^{\mathrm{T}} \mathrm{d} u=\int \ddot{\mathbf{u}}_{\mathrm{t}}^{\mathrm{T}} \mathbf{M} \mathrm{d} u+\int \mathbf{p}^{\mathrm{T}} \mathrm{d} u .
$$

The three terms on the left side of equation (17) successively represent as the absolute kinetic energy $\left(E^{K}\right.$, which can be evaluated in a time step using the absolute velocity vector), the dissipated energy due to viscous damping $\left(E_{C}\right)$, and the internal work done by nonlinear restoring forces
$\left(E^{R}\right)$. The two terms on the right side of equation (17) successively represent as the seismic input energy $\left(E_{W Q}\right)$ and the work done by preseismic applied loads $\left(E^{W P}\right)$.

The work done by the nonlinear restoring force can be expressed as follows:

$$
\begin{aligned}
E^{R}= & \int_{0}^{\mathrm{T}} \int_{V} \frac{1-d_{T}}{1-d} \sigma^{r} \varepsilon^{\mathrm{el}} \mathrm{d} V \mathrm{~d} t+\int_{0}^{\mathrm{T}} \int_{V} \frac{d_{T}-d}{1-d} \sigma^{r} \varepsilon^{\mathrm{el}} \mathrm{d} V \mathrm{~d} t \\
& +\int_{0}^{\mathrm{T}} \int_{V} \sigma^{r} \varepsilon^{\mathrm{el}} \mathrm{d} V \mathrm{~d} t=E^{E}+E^{D}+E^{P} \varepsilon^{\mathrm{el}},
\end{aligned}
$$

where $d_{T}$ is the damage value; $\sigma^{r}$ represents the nonlinear recovery stress; $\varepsilon^{\mathrm{pl}}$, respectively, represents the elastic and plastic strain; $E^{E}$ is expressed as recoverable strain energy; and $E^{D}$ and $E^{P}$, respectively, represent the damage and plastic dissipation energy.

\subsection{Dam Body and Foundation Whole Dissipated Energy} Characteristics. For the calculation results of seismic damage in Section 3, this article analyzes and compares two dissipated energy indicators: damage dissipated energy (ALLDMD) and plasticity dissipated energy (ALLPD), as shown in Figures 9 and 10. After the single main shock, the whole damage and plastic dissipated energy of concrete gravity dams are 16.76 and $41.19 \mathrm{kN} \cdot \mathrm{m}$, respectively. Under the main-aftershock, when the aftershock is small (condition a), the energy consumption of the concrete gravity dam has no obvious change compared with those under a single main shock. This shows that after the main shock, smaller aftershock cannot cause the secondary dissipated 

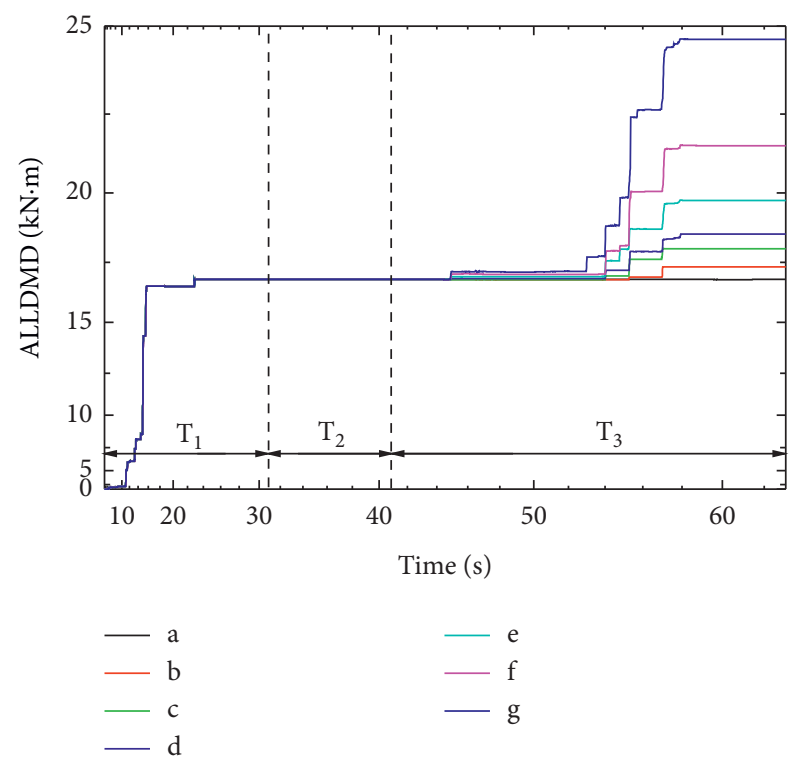

Figure 9: Damage dissipated energy.

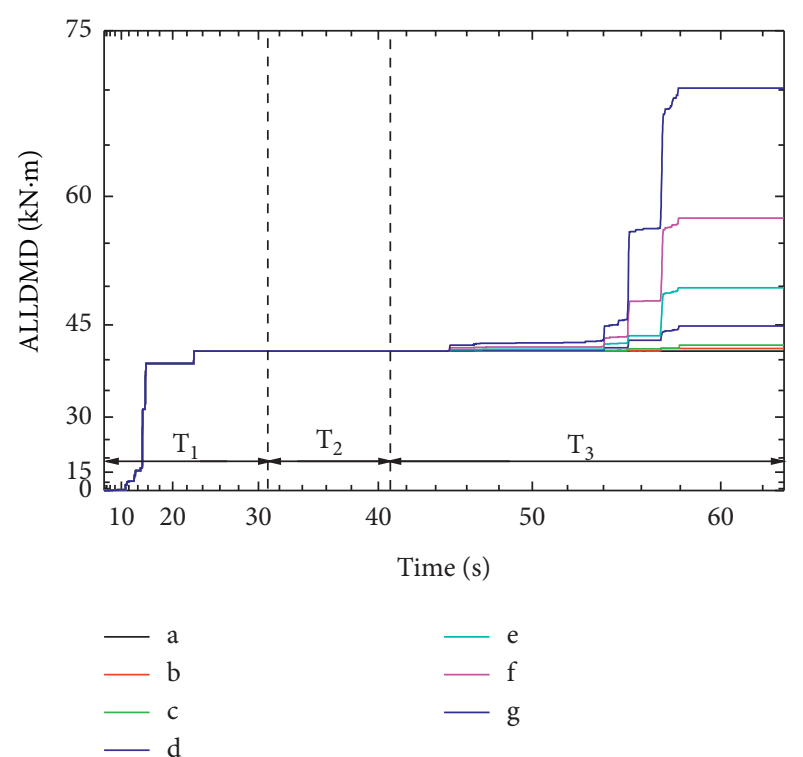

Figure 10: Plastic dissipated energy.

energy of the concrete gravity dam. With the decrease in aftershock PGA transcendence probability (the intensity of aftershocks is increasing), the damage and plastic dissipated energy of the concrete gravity dam have different degrees of secondary dissipation process. Compared with the single main shock, the whole damage energy of the condition $\mathrm{b} \sim \mathrm{g}$ is increased by $2.73 \%, 7.02 \%, 11.53 \%$, $17.45 \%, 25.43 \%$, and $46.82 \%$, respectively, and the plastic dissipated energy of the condition $\mathrm{b} \sim \mathrm{g}$ is increased by $0.82 \%, 3.02 \%, 8.57 \%, 20.49 \%, 40.12 \%$, and $71.83 \%$, respectively. Therefore, under the effects of aftershocks with different transcendence probability, the whole damage and plastic strain of the concrete gravity dam have cumulative effects of varying degrees.

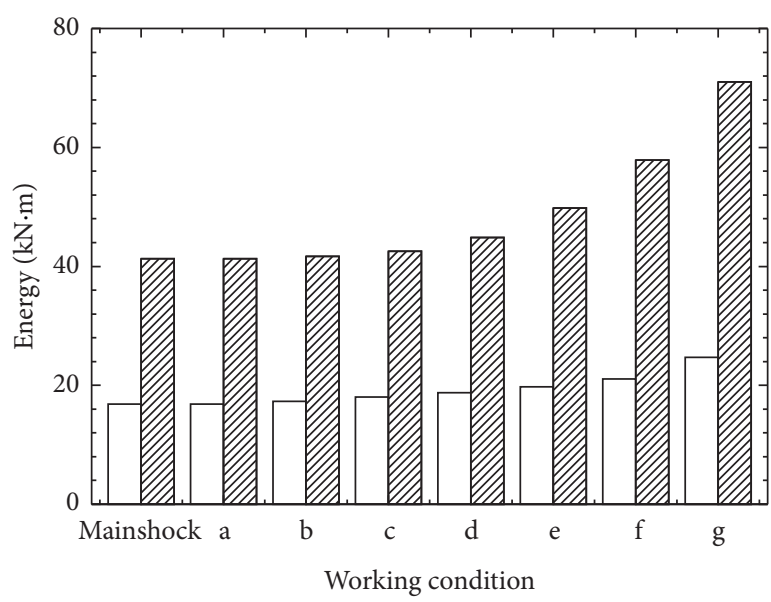

ALLDMD

VIIA ALLPD

Figure 11: Dam dissipated energy.

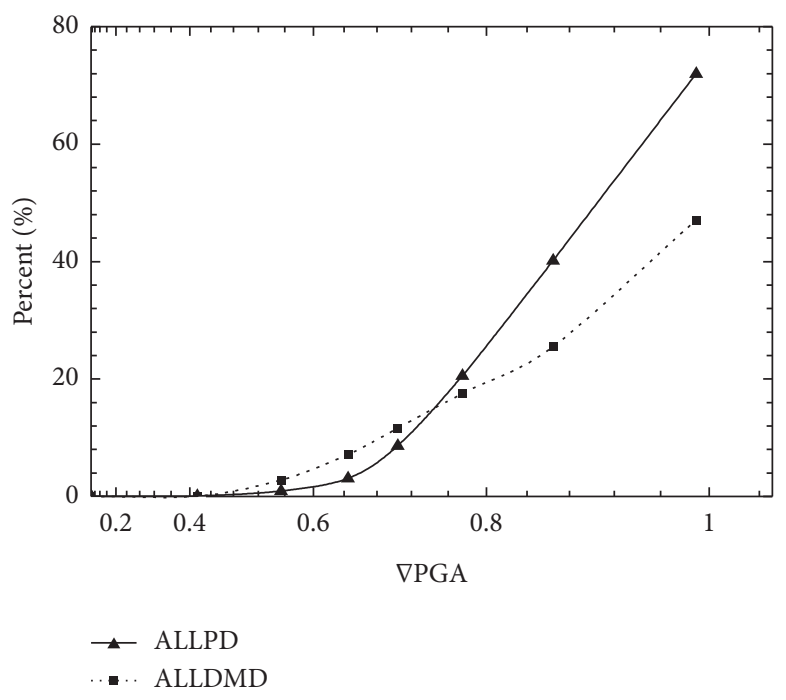

FIGURE 12: Dissipated energy growth rate.

Figure 11 shows the whole dissipated energy of the concrete gravity dam after the earthquake. The whole plastic dissipated energy is bigger than the damage dissipated energy of the dam. Figure 12 shows the fitting curve of dam dissipated energy growth rate varying with $\nabla P G A$, where the transverse axis is the ratio ( $\nabla P G A)$ of aftershock peak acceleration to main shock peak acceleration and the vertical axis is the dissipated energy growth rate (the same below). The corresponding $\nabla \mathrm{PGA}$ of the condition a $\mathrm{g}$ is 0.415 , $0.555,0.645,0.705,0.775,0.865$, and 0.990 , respectively. It can be seen from Figure 12, with the increase in $\nabla$ PGA, the whole damage and plastic dissipated energy of the concrete gravity dam show different changes. When $\nabla P G A \leq 0.44$ (the transcendence probability of the aftershock PGA is $61.5 \%$ ), the aftershock action can not cause further damage to the dam. When $0.44<\nabla P G A<0.74$, the whole damage 
dissipated energy growth rate of the dam is greater than the plastic dissipated energy growth rate. However, when $0.74 \leq \nabla \mathrm{PGA}$ (the transcendence probability of the aftershock PGA is $22.3 \%$ ), the whole plastic dissipated energy growth rate of the dam is greater than the damage dissipated energy growth rate.

On the whole, the fitting curve of the dam damage dissipated energy growth rate caused by the aftershock is flatter than the plastic dissipated energy growth rate. In order to quantify the cumulative damage effect of aftershock on the dam, this paper takes the dissipated energy growth rate of $10 \%$ as the critical point that the aftershock cause large secondary damage to the dam. At this time, the VPGA corresponding to the fitted curve of the whole damage and plastic dissipated energy growth rate is 0.68 and 0.71 , respectively. Then, substituting them into equation (4), the aftershock transcendence probability of $27.1 \%$ and $24.5 \%$, respectively, is obtained.

4.3. Dissipated Energy Characteristics of Dam Body and Foundation. Under different conditions, the dissipated energy of the dam body is shown Figure 13. Similar to the whole dissipated energy of the dam, when the aftershock intensity is small, the dissipated energy of the dam body has no obvious change compared with those under a single main shock. And, the plastic dissipated energy of the dam body under different conditions is greater than that of the damage dissipated energy. Figure 14 shows the fitting curve of the dissipated energy growth rate of the dam body varying with $\nabla$ PGA. When $\nabla P G A \geq 0.46$, the whole damage and plastic dissipated energy of the dam body increase with the increase in $\nabla$ PGA, but the variation trend is not the same. When $0.46<\nabla P G A<0.74$, there is little difference between the two variations. When $0.74 \leq \nabla P G A$, with the increase in $\nabla P G A$, the increasing rate of plastic dissipated energy of dam body is obviously higher than that of damage dissipated energy of dam body, which indicates that strong aftershock can cause greater plastic strain of the dam body.

Under different conditions, the dissipated energy of the dam body is shown Figure 15. Similar to the dam body, the plastic dissipated energy of the dam foundation under different conditions is greater than the damage dissipated energy. Fitting curve of dissipated energy growth rate of dam foundation varying with $\mathrm{PPGA}$ is shown in Figure 16. Similar to the whole energy characteristics of the concrete gravity dam, when $\nabla P G A \leq 0.44$, the aftershock action did not cause further damage to the dam foundation. When $0.44<\nabla \mathrm{PGA}<0.74$, the growth rate of the dam foundation plastic dissipated energy is greater than the damage dissipated energy growth rate. However, when $0.74 \leq \nabla$ PGA, the plastic dissipated energy growth rate of the dam foundation is greater than the damage dissipated energy growth rate. On the whole, the fitting curve of plastic dissipated energy growth rate of the dam foundation is steeper than that of damage dissipated energy growth rate.

Compare Figures 13 and 15. Under different conditions, the cumulative effect of aftershocks on the damage of dam

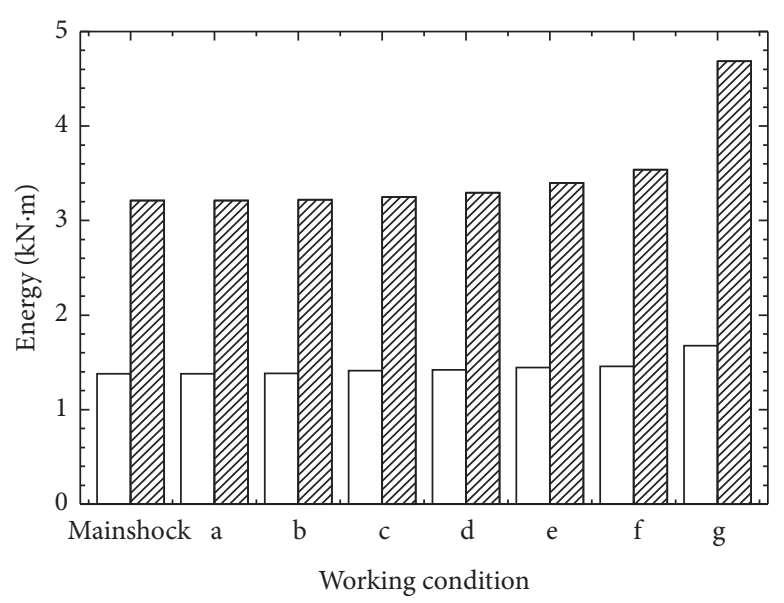

ALLDMD

एIII ALLPD

FIgURe 13: Dam body dissipated energy.

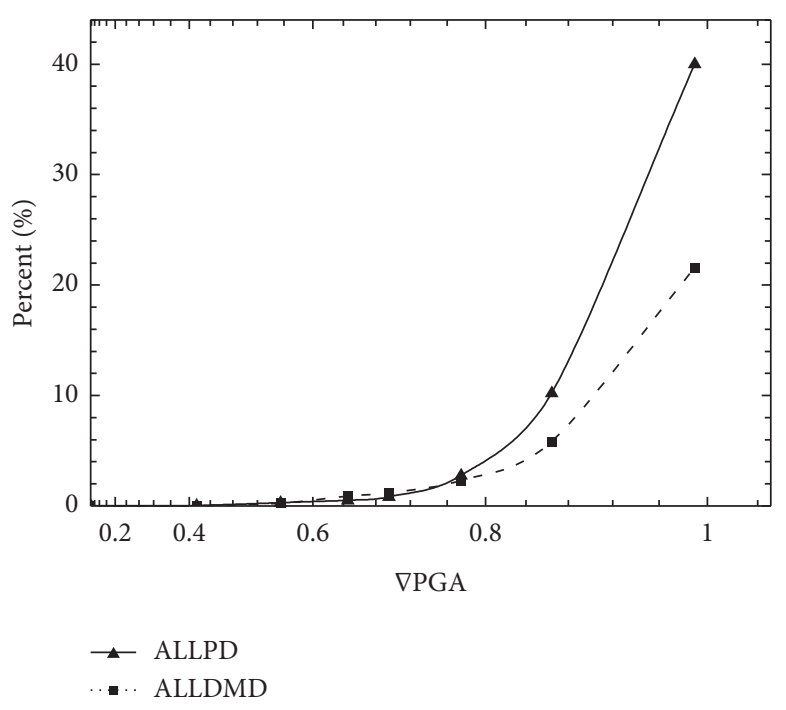

FIgURe 14: Dissipated energy growth rate.

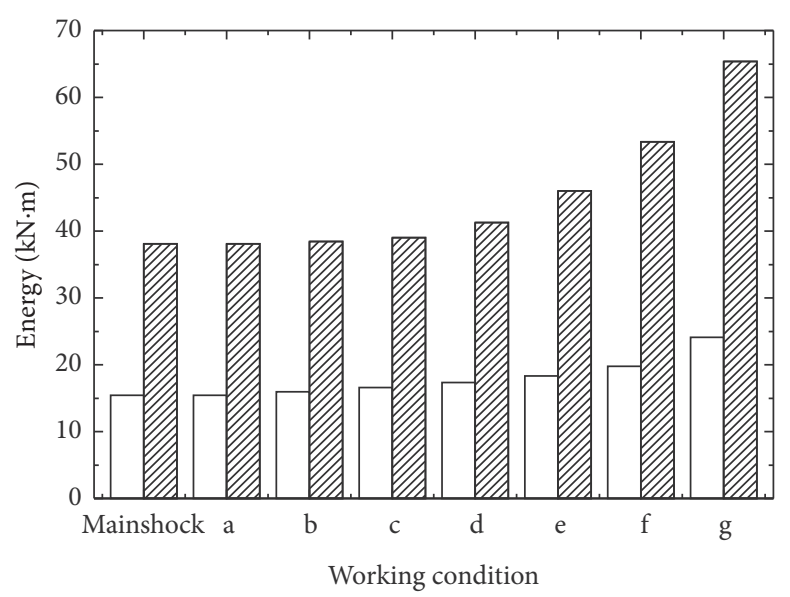

ALLDMD

ALLPD

Figure 15: Dam foundation dissipated energy. 


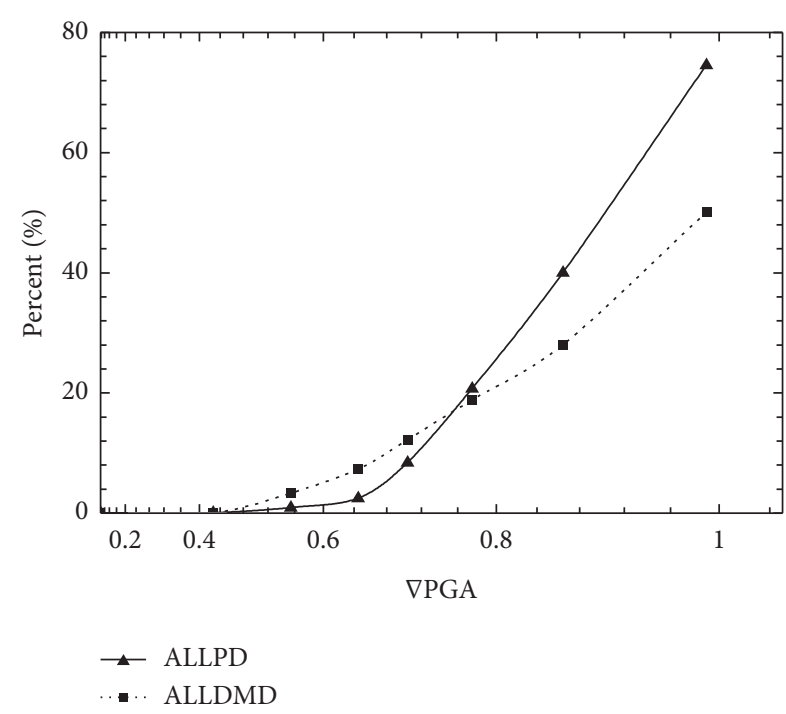

FIgURE 16: Dissipated energy growth rate.

foundation is more significant than that of dam body. For example, when $\nabla \mathrm{PGA}=0.9$, the dam body damage and plastic dissipated energy increased by $10.3 \%$ and $22.7 \%$, respectively, while the dam foundation damage and plastic dissipated energy increased by $35.2 \%$ and $50.4 \%$, respectively.

\section{Conclusion}

On the basis of the previous research results and with the randomness of ground motion taken into consideration, a new method for main-aftershock sequence construction based on probability is proposed in this paper, which is intended for the seismic analysis under different main-aftershock ground motion sequences with different aftershock transcendence probabilities. The integral damage model of the dam system is established, with the theory of plastic damage mechanics applied for the analysis of the rock material. And then, the research on nonlinear dynamic response of concrete gravity dams with different aftershock transcendental probabilities is carried out. The main research results of this paper are as follows:

(1) In this paper, the appropriate statistical relationship of the main shock and aftershock magnitude is selected, the attenuation relationship of aftershock ground motion parameters considering the nearfield saturation effect is introduced, the transcendental probability $(\mathrm{P})$ is utilized to represent the statistical characteristics of the aftershock intensity, and a method for determining the ground motion input parameters of the main-aftershock sequence is eventually proposed.

(2) Different from merely considering the damage characteristics of the dam body materials, this paper considers the damage of the rock material at the dam foundation under earthquake and it turns out that the cracks at the dam heel appear to expand downward in the depth direction, which may cause severe irreversible deformation of the dam foundation. Therefore, it should be taken seriously in the seismic analysis of concrete gravity dams.

(3) Under the action of the main-aftershock, the damage and plastic dissipated energy of the dam have shown different growth laws with the decrease in the transcendence probability (P) of the aftershock DPGA. It turns out that the cumulative effects of aftershock on the damage and plastic strain of the dam foundation are more significant than those of the dam body. In addition, when $\nabla \mathrm{PGA} \leq 0.44$ (the aftershock transcendence probability is about $61.5 \%)$, the aftershock action will not cause further damage to the dam, whereas when $\nabla$ PGA $>0.68$ (the aftershock transcendence probability is about $27.1 \%$ ), the aftershock action will cause large secondary damage to the dam structure.

It should be noted that this article only considers bedrock materials as the initial state. Actually, after consolidation and grouting of the dam foundation, its elastic modulus and tensile strength will be improved upon. In addition, though a series of values are selected for the transcendental probability of the relative peak acceleration of the main-aftershock in this paper, how to choose appropriate transcendental probability in the design still needs to be further studied on.

\section{Data Availability}

The data used to support the research of this article are listed within the article or marked with references in the corresponding position.

\section{Conflicts of Interest}

The authors declare that they have no conflicts of interest regarding the publication of this paper.

\section{Acknowledgments}

This research was financially supported by the Nation Key Research and Development Plan of Ministry of Science and Technology of the People's Republic of China (2017YFC0404903).

\section{References}

[1] E. Omranian, A. E. Abdelnaby, and G. Abdollahzadeh, "Seismic vulnerability assessment of RC skew bridges subjected to Mainshock-Aftershock Sequences," Soil Dynamics and Earthquake Engineering, vol. 114, pp. 186-197, 2018.

[2] F. Jalayer and H. Ebrahimian, "Seismic risk assessment considering cumulative damage due to aftershocks," Earthquake Engineering \& Structural Dynamics, vol. 46, no. 3, pp. 369-389, 2016.

[3] H. V. Burton, S. Sreekumar, M. Sharma, and H. Sun, "Estimating aftershock collapse vulnerability using mainshock intensity, structural response and physical damage indicators," Structural Safety, vol. 68, pp. 85-96, 2017. 
[4] J. M. Dulinska and I. J. Murzyn, "Seismic performance of a concrete highway tunnel under earthquake sequence using a concrete damage plasticity model," Key Engineering Materials, vol. 725, pp. 110-115, 2016.

[5] Q. Li and B. R. Ellingwood, "Performance evaluation and damage assessment of steel frame buildings under main shock-aftershock earthquake sequences," Earthquake Engineering \& Structural Dynamics, vol. 36, no. 3, pp. 405-427, 2007.

[6] GB, "Ministry of water resources of the PRC Standard for seismic design of hydraulic structures China," 2018.

[7] G. L. Yeo and C. A. Cornell, "A probabilistic framework for quantification of aftershock ground-motion hazard in California: methodology and parametric study," Earthquake Engineering \& Structural Dynamics, vol. 38, no. 1, pp. 45-60, 2009.

[8] S. Das and V. K. Gupta, "Scaling of response spectrum and duration for aftershocks," Soil Dynamics and Earthquake Engineering, vol. 30, no. 8, pp. 724-735, 2010.

[9] D. M. Boore, J. P. Stewart, and E. Seyhan, "NGA-West2 equations for predicting PGA, PGV, and 5\% damped PSA for shallow crustal earthquakes," Earthquake Spectra, vol. 30, no. 3, pp. 1057-1085, 2014.

[10] V. Graizer and E. Kalkan, Update of the Graizer-Kalkan Ground-Motion Prediction Equations for Shallow Crustal Continental Earthquakes, US Geological Survey Open-file Report, Reston, VA, USA, 2015.

[11] V. Vahedian, E. Omranian, and GR. Abdollahzadeh, "A new method for generating aftershock records using artificial neural network," Journal of Earthquake Engineering, vol. 4, 2019.

[12] P.-M. Alliard and P. Léger, "Earthquake safety evaluation of gravity dams considering aftershocks and reduced drainage efficiency," Journal of Engineering Mechanics, vol. 134, no. 1, pp. 12-22, 2008.

[13] C. Wang and S. R. Zhang, "Damage evolution and dissipated energy characters of gravity dam under mainshock-aftershock earthquake sequences," Journal of Earthquake Engineering and Engineering, vol. 33, no. 4, pp. 51-56, 2013.

[14] G. Wang, Y. Wang, and W. Lu, "Earthquake direction effects on seismic performance of concrete gravity dams to mainshock-aftershock sequences," Journal of Earthquake Engineering, vol. 22, 2018.

[15] GR. Abdollahzadeh, E. Omranian, and V. Vahedian, “Application of the artificial neural network for predicting mainshock-aftershock sequences in seismic assessment of reinforced concrete structures," Journal of Earthquake Engineering, vol. 27, 2018.

[16] H. Q. Chen, D. Y. LI, and G. S-S, "Damage-rupture process of concrete dams under strong earthquakes," International Journal of Structural Stability and Dynamics, vol. 14, no. 7, pp. 1-21, 2014.

[17] W. S. Ding, "Seismic Design Method and Experimental Study on Rigid-Frame through Tied-Arch Bridges," Ph.D. Thesis, College of Civil Engineering, Southeast University, Nanjing, China, 2006.

[18] C. H. Zhai and L. L. Xie, Mainshock-aftershock Earthquake Ground Motion Characteristics and Structural Damage Analysis, Science Press, Beijing, China, 2017.

[19] M. Amin and A. H.-S. Ang, "Nonstationary stochastic models of earthquake motions," Journal of the Engineering Mechanics Division, vol. 94, no. 2, pp. 559-584, 1968.
[20] J. R. Huo, "Study on envelope function of acceleration time history," Earthquake Engineering and Engineering Dynamics, vol. 1, pp. 1-12, 1991.

[21] M. C. Chapman, C. A. Powell, and G. Vlahovic, "A statistical analysis of earthquake focal mechanisms and epicenter locations in the eastern Tennessee seismic zone," Bulletin of the Seismological Society of America, vol. 87, no. 6, pp. 1522-1536, 1997.

[22] J. Lee and G. L. Fenves, "A plastic-damage concrete model for earthquake analysis of dams," Earthquake Engineering \& Structural Dynamics, vol. 27, no. 9, pp. 937-956, 1998.

[23] P. M. Grassl, "Damage-plastic model for concrete failure," International Journal of Solids and Structures, vol. 43, no. 2223, pp. 7166-7196, 2006.

[24] Y. Jirásek and Z. Bi, "Study on damage and failure of gravity dam under main aftershock sequence based on NGA Model," Journal of Hydraulic Engineering, vol. 51, no. 2, pp. 152-168, 2020.

[25] S. Zhang, G. Wang, and W. Sa, "Damage evaluation of concrete gravity dams under mainshock-aftershock seismic sequences," Soil Dynamics and Earthquake Engineering, vol. 50, pp. 16-27, 2013.

[26] G. Wang, Y. Wang, W. Lu, P. Yan, W. Zhou, and M. Chen, "Damage demand assessment of mainshock-damaged concrete gravity dams subjected to aftershocks," Soil Dynamics and Earthquake Engineering, vol. 98, pp. 141-154, 2017. 